\title{
Quality improvement of traditional rice liquor (srasor) processing in Takeo Province, Cambodia
}

\author{
${ }^{1,2 *}$ Chay, C, ${ }^{2}$ Dizon, E.I., ${ }^{3}$ Elegado, F.B., ${ }^{1}$ Norng, C., ${ }^{4}$ Hurtada,W.A. and ${ }^{2}$ Raymundo, L.C. \\ ${ }^{1}$ Royal University of Agriculture, Phnom Penh, Cambodia \\ ${ }^{2}$ Institute of Food Science and Technology, College of Agriculture and Food Science, University of the \\ Philippines Los Baños, College, Laguna - 4031, Philippines \\ ${ }^{3}$ The National Institute of Molecular Biology and Biotechnology (BIOTECH), University of the Philippines \\ Los Baños, College, Laguna - 4031, Philippines \\ ${ }^{4}$ Institute of Human Nutrition and Food, College of Human Ecology, University of the Philippines Los
}

Baños, College, Laguna-4031, Philippines

\section{Article history:}

Received: 14 February 2018

Received in revised form: 16 March 2018

Accepted: 18 March 2018

Available Online: 24 March 2018

\section{Keywords:}

Physicochemical properties, Sanitation practices,

Traditional rice liquor (srasor),

Process modification

\section{DOI:}

https://doi.org/10.26656/fr.2017.2(4).038

\begin{abstract}
Distribution of Cambodia's rice liquor, srasor, is limited only to some local areas due to its poor and inconsistent quality. The study, in general, aimed to improve the quality of srasor through identification of the technical issues and other factors affecting product's quality. Specifically, the study focused to modify the traditional process of srasor production; conduct trial production to evaluate the effectiveness of the modified techniques, and determine the quality of the resulting product through physicochemical properties evaluation. Simple production cost analysis was also conducted. Process modifications of the traditional method of srasor processing were done through the implementation of proper sanitation practices, rice cooking method, fermentation condition, and technique of distillation. Results revealed that the yield and alcohol content of the product using the modified method significantly increased. Adoption of the improved method also resulted in the profitability of rice liquor production.
\end{abstract}

\section{Introduction}

Alcoholic beverages, including beers, wines, and spirits, are important indigenous fermented products worldwide, particularly in Asian countries. They play important roles in the celebration of special occasions (Lisdiyanti and Kozaki, 2003). Depending on the availability of ingredients in the regions and manufacturing practices, rice wines are known under a variety of local names. The manufacture of rice wine is characterized as a biological process wherein rice (Oryza sativa L.) is converted into wine by physical and chemical alterations through the use of useful microorganisms or enzymes. By distillation of the fermented rice, rice liquor with approximately $50 \% \mathrm{v} / \mathrm{v}$ (about $40 \% \mathrm{w} / \mathrm{v}$ ) alcohol content can be obtained (Alan, 2011).

The Phnom Penh populations are not all familiar with Cambodian's rice liquor because of its limited distribution triggered by low-quality product. Although rice liquor production is one of the common processed agricultural products in the rural areas of Cambodia, the producers faced the problem of low profitability in their business. Low-quality rice liquor is characterized by acidic taste, spoiled aroma, muddy and smoky smell/ taste, cloudy and undesirable color. Thus, it is of utmost concern to improve the quality of the product in terms of physicochemical and sensory properties, yield and establish the quality control system throughout the processing operation. Quality improvement of rice liquor would be one of the key strategies to increase the sales of rice liquor and be competitive both in national and international markets. This will eventually give additional income to the local liquor producers and improve the country's economy as well.

The study aimed to improve the quality of Cambodian rice liquor through process modification of the existing methods and practices.

\section{Materials and methods}

\subsection{Target area}

The study was conducted in Ta Toem Village, CheangToung Commune, Tramkak District, Takeo Province, Cambodia. This is where the local farmer 
collaborator manufactured their product and demonstrated srasor processing during the conduct of the study.

\subsection{Identify technical issue and technical modification}

Identify technical issue which causes low quality of rice liquor based on observation of production process of a cooperating producer.By using the prototype, a series of quality improvement trials was conducted to examine a potential of the techniques for improving the quality suggested from observation.

In the trials, the common raw materials for fermentation were used as the cooperative producer did. The starter was called 'meesraa' in Cambodia. The meesraa got from the markets of Takeo province. Meesraa except had both molds for saccharification and yeast for alcohol fermentation.

\subsection{Traditional method of srasor processing}

Documentation of the traditional method of actual processing of srasor was done to get first-hand information on how the improvement of the process can be done. The local producer used ordinary milled rice as raw materials for making srasor. After washing, the rice was added with an estimated volume of pond water and boiled until well done for 60 to 90 minutes using firewood, spread on the plastic mat for cooling, and added with an estimated amount of mésraa or medombae (dried starter culture) based on their experience. Dried starter culture buys from the local market but it is imported from the neighbor country. Dried starter culture, it is kind of mix mold and yeast. After mixing the steamed rice and powdered starter culture, the inoculated rice was placed in an earthenware jar for 2 days solid state fermentation, and another 2 days for liquid state fermentation with the addition of water. The fermented rice was transferred to the distillation pot and the distillate or the resulting alcoholic beverage contained about $30-35 \%$ alcohol. Prior to selling in the market, the manufacturer diluted the product with water to have an estimated final alcohol content of $15-25 \%$. The product was placed in a 20 L-capacity plastic container.

\subsection{Process modification of srasor processing}

In general, modification or improvement of the current traditional method of srasor processing was done by implementation of proper cleaning and sanitation of the containers, measuring devices and gadgets, use of potable water, use of proper instrument for measurement of temperature, measured amount of water during cooking of rice, proper fermentation conditions, and modification of processes during distillation of fermented rice.

\subsubsection{Water source for processing}

The traditional technique of processing rice liquor used the pond water characterized by muddy smell and wild microorganisms are likely to be present in it. Thus, potable or drinking water was used for srasor processing to ensure safe and good quality product.

\subsubsection{Cooking of rice}

Modification in the cooking of rice was made. Milled rice was weighed, soaked and washed 2 to 3 times with clean water to remove the rice bran and hull until the water becomes clear and then drained. The washed rice was steamed for 90 minutes with interval stirring using a bamboo stick and sprayed with water during the course of cooking. In the first stirring, the amount of water for spraying is equal to the amount of rice, while in the second stirring, the amount of water is half the amount of the first batch added. After steaming, the cooked rice was taken out from the fire and placed on a clean mat to cool.

\subsubsection{Inoculation (mixing rice with starter culture)}

The steamed rice was taken out from the pan and spread thinly on a plastic mat to cool at room temperature within the range of 35 to $38^{\circ} \mathrm{C}$, determined using an alcohol-sanitized thermometer. Powdered starter culture ( $2.5 \%$ based on the weight of milled rice) was sprinkled on the surface of the steamed rice and mixed well for uniform distribution. Then the inoculated steamed rice was weighed and transferred in the fermentation vat.

\subsubsection{Rice liquor fermentation}

The early stage of fermentation is known as solid state fermentation (SSF) wherein the steamed rice was mixed with powdered starter culture and placed in a fermentation jar as mentioned above. The temperature of fermentation was observed daily for 48 hours. This is followed by liquid state fermentation (LSF) wherein after 48-hour fermentation, water was added in each fermentation jar at the rate of 1 part milled rice to 3 parts water. The fermentation temperature was regulated during hot and cold temperature: during hot temperature, only a few layers of plastic for covering fermentation vats were used, while during cold temperature the vats are covered with several layers of plastic to make a warm temperature.

\subsubsection{Distillation of rice liquor}

The process of distillation was modified by separating the liquid from the solid portion of the 
fermented rice mash using an aluminum tray with small holes that allowed the liquid to drop but not the solid portions. The first few dripping was collected and separated as this contains low boiling point alcohol that might contain methanol known to be the toxic compound in most alcohol distillates.

\subsection{Physicochemical properties of the rice liquor using traditional and modified method}

The rice liquor was subjected to analysis of $\mathrm{pH}$, TSS, Total acidity described by AOAC (2000) and determined as follows:

\section{$2.5 .1 \mathrm{pH}$}

$\mathrm{pH}$ meter was calibrated using $\mathrm{pH}$ buffers 4 and 7 . Then enough amount of sample was placed in a beaker and the $\mathrm{pH}$ was recorded.

\subsubsection{Total soluble solids (TSS, ${ }^{\circ}$ Brix)}

The sample was placed on the prism of a hand refractometer and then the value, where sharp boundary line of light and dark area meets, was recorded.

\subsubsection{Total acidity (TTA)}

Ten $\mathrm{ml}(10 \mathrm{~mL})$ of each sample was pipetted and place in an Erlenmeyer flask, then 2-3 drops of phenolphthalein were added. This was titrated using standardized $0.1 \mathrm{~N} \mathrm{NaOH}$ until faint pink color appeared. The TTA was calculated using the formula below:

$\mathrm{TTA}=\mathrm{V}_{\mathrm{NaOH}} \times \mathrm{F}$

where :

$$
\mathrm{F}=\frac{0.1 \mathrm{~N} \mathrm{NaOH}}{\text { Standardized } \mathrm{NaOH}}
$$

\subsubsection{Alcohol content (\%)}

An approximately $100 \mathrm{~mL}$ of the rice liquor was obtained and placed in refrigerated for 15 minutes (or until the temperature of the rice liquor reached $15^{\circ} \mathrm{C}$ ). The alcohol meter was allowed to float freely on the sample and the alcohol content was recorded. The reading was expressed as $\%$ alcohol $(\mathrm{v} / \mathrm{v})$.

On the other hand, the percent pure alcohol content of the distilled fermented rice extract and the yield of rice liquor (\%) using the traditional and modified method of processing srasor was computed as:

Purealcohol $(L)=\frac{\text { AlcoholicVolume }(L) \times \text { Alcoholic percentage }(\%)}{100}$

Yield $(L / K g)=\frac{\text { Purealcohol }(L)}{\text { Weight of rawrice }(K g)}$
Percentage yield $=\frac{\text { Volume of liquor }(L)}{\text { Weight of rawrice }(K g)} \times 100$

\subsection{Production cost of rice liquor processing}

Net profit margin or net profit ratio which refer to as the measure of profitability was calculated. The net profit was calculated as a percentage change in the revenue.

Total Revenue $(\mathrm{TR})=\mathrm{Q}$ x $\mathrm{P}$

Where $\mathrm{Q}=$ Quantify of product $(\mathrm{L}), \mathrm{P}=$ Price of product (USD)

Net Profit $=$ TR - Total cost

Profit percentage $(\%)=($ TR modified - TR traditional $) /$ TR traditional $\mathrm{x} 100$

\subsection{Sensory test evaluation}

The rice liquors produced with quality improvement trials were evaluated in production stability. The final candidates of quality rice liquor overcame the issues were provided to consumer test. Local product rice liquor purchased from a local farmer was used as a control or original production before improvement. It was confirmed that the local liquor was produced with the common production process in the area. The degree of trial liquor was adjusted to $32 \%$ to be the same degree with rice liquor that of local one. Tastings and interviews were carried out to the three hundred general costumers or visitors in One Province One Product Exhibition in Phnom Penh. They were asked to taste both liquors and respond to the questionnaires on the preference level of the trial one.

\subsection{Statistical analysis}

Data were analyzed using Analysis of Variance (ANOVA). Samples found to be significantly different were further subjected to Duncan's New Multiple Range Test (DNMRT) to locate which among the samples are different.

\section{Results and discussion}

\subsection{Traditional practices of rice liquor (srasor)} processing

Actual observations of srasor processing revealed that the local manufacturers do not follow Good Manufacturing Practices (GMP) guidelines. Proper sanitation and personal hygiene are not implemented at all. GMP covers the entire manufacturing spectrum, from raw material to the final products, covering processing, equipment, buildings, and personnel. Most of the sources of contamination were observed to be related 
to the equipment and utensils used in processing.

Sanitation is most crucial for rice liquor processing. The pots or fermentation vats were dirty or unclean, wet and with visible mold growth. Proper use of sanitizers or detergent for washing followed by rinsing and drying of containers particularly under the sun should be applied since the sunlight is capable of destroying or inactivating microorganisms. The unsanitized fermentation jars will cause microbial contamination of the fermenting rice wine. The bed for mixing cooked rice was also rarely cleaned and stray dogs, ducks, and chickens were observed entering the processing area. These are potential sources of biological and physical contaminations to cooked rice during cooling and mixing steps. During fermentation, the fermentation containers were placed directly on the soil flooring. This practice is not suitable for fermentation because the container may imbibe moisture from the soil especially during rainy season. There must be a separate room for fermentation.

Plastic nets (Figure 1) used for mixing cooked rice with starter culture are rarely washed and dried. This causes sour smell or putrefied smell and contamination during inoculation stage. The nets should be washed and dried every after use to prevent cross-contamination. The distilling pot (in and out) was observed too dirty caused by solidified. Distillation equipment should be kept clean at all times because it will affect the quality of the final product. It was also observed that the surroundings of the distillation area are full of scattered garbage. Proper disposal of both solid and liquid processing wastes should be implemented and regular integrated pest management practices should be in place. To sum up, acidic and putrefied smell of the finished product was caused by poor sanitation practices.

Norman and Robert (2006) reported that basic sanitation principles supported by the wine institute include: 1) A winery should be kept free of refuse both inside and outside; 2) Equipment should be arranged in an orderly way and the work areas kept free of clutter; 3 ) The entire winery should be cleaned on a regularly scheduled basis; 4) The winery should be protected against harmful bacteria, yeasts, molds, insects, and rodents with necessary measures to prevent a recurrence of these pests in the future; and 5) The winery premises, equipment, and cooperage should be inspected at least once each month.

\subsection{Improvement/modification of traditional srasor processing}

To improve the quality of the product, modification of the current method of srasor processing was done following the guidelines of Good Manufacturing
Practices (GMP). Table 1 presents the approach done to ascertain that the conditions prescribed by GMP are met by the facilities and processing operations. The ultimate goal of proper hygiene is to prevent contamination of ingredients, products or packaging. In general, implementation of proper cleaning and sanitation of the containers, use of measuring devices and gadgets, use of potable water, use of proper instrument for measurements of temperature, exact measurement of potable water for cooking of rice, proper fermentation conditions, and modification of processes during distillation of fermented rice must be performed during rice liquor processing.

\subsubsection{Water source for processing}

The traditional processing of rice liquor used the pond water and there is no assurance that this is safe as revealed by the muddy smell, and wild microorganisms may have been present in it. The water used in a winery must have certain limit for chemical and microbial properties. A low $\mathrm{pH}$ is inimical to steel and other surfaces and a high $\mathrm{pH}$ will favor calcium precipitation. The biochemical oxygen demand (BOD) should be $<3$ $\mathrm{mgL}^{-1}$. Water can be a potential carrier of molds, yeasts, and acetic or lactic acid bacteria, thus potable or drinking water should be used for processing. The water for sake brewing need to be colorless, tasteless, and odorless with neutral or weakly alkaline $\mathrm{pH}$, and contain only trace amounts of iron $(<0.02 \mathrm{ppm})$, ammonia, nitrite, and organic substances, and no harmful microorganisms. Several ions, especially potassium, contained in water in minor concentrations have been reported to affect rice wine fermentation (Kiyoshi and Takeaki, 2004).

\subsubsection{Cooking of rice}

Instead of the ordinary method of cooking rice by boiling until well done, the washed rice was steamed for a total 90 minutes in a double layer steamer with interval stirring using a bamboo stick and spraying with proper amount of water. After the cooking process, the cooked rice is taken out from fire and placed on a mat to cool. In the traditional process, liquor processors preferred to boil the rice since it will take shorter time than steaming. However, this method will caused burning of rice due to uncontrolled heat of the fire. The burned rice affects the quality of the product particularly its flavor. In addition, the separation of scorched rice will cause low yield. On top of these concerns, is the setting of burned rice at the bottom of the distilling pot and be burned contributing to more disagreeable flavor of the rice liquor. Therefore, steaming is a better method for cooking rice even if it spends longer time than direct boiling since the rice is cooked well without burning. The rice is steamed for 4060 min during which time the starch is changed to $\alpha$ form 
Table 1. Process modification of traditional rice liquor processing

\begin{tabular}{|c|c|c|}
\hline Parameter & Traditional Method & Modified Process \\
\hline \multirow{4}{*}{$\begin{array}{l}\text { During rice liquor } \\
\text { processing }\end{array}$} & Dirty pots/containers & Cleaned, washed, and sun-dried \\
\hline & Dirty plastic net & Washed and dried \\
\hline & Garbage, scattered & Proper waste disposal \\
\hline & Dirty distillation pan & Cleaned distillation pan \\
\hline Water used & Pond water & Deep well water \\
\hline Cooking method & Boiling until well done in open kettle & Steam-cooking \\
\hline \multirow{2}{*}{$\begin{array}{l}\text { Mixing steamed/boiled } \\
\text { rice }\end{array}$} & $\begin{array}{l}\text { Cooling of cooked rice (Estimate temperature } \\
\text { by hand) }\end{array}$ & $\begin{array}{l}\text { Cooling of cooked rice (Determined using a } \\
\text { thermometer) }\end{array}$ \\
\hline & Estimate amount of boiled rice & Weighed amount of steamed rice \\
\hline \multirow{6}{*}{ During fermentation } & $\begin{array}{l}\text { Keep fermenting rice in jars without } \\
\text { monitoring the condition }\end{array}$ & Monitored temperature and checked \\
\hline & Seldom changed and cleaned plastic bag cover & $\begin{array}{l}\text { Changed, cleaned and dried plastic bag } \\
\text { regularly }\end{array}$ \\
\hline & $\begin{array}{l}\text { Estimate the amount of water added for liquid } \\
\text { fermentation }\end{array}$ & $\begin{array}{l}\text { Measured the amount of water added for liquid } \\
\text { fermentation }\end{array}$ \\
\hline & $\begin{array}{l}\text { Fermentation vat directly placed on the floor/ } \\
\text { soil }\end{array}$ & Fermentation vat using hardwood as support \\
\hline & $\begin{array}{l}\text { Producers do not make any adjustments on the } \\
\text { cover of the jar during cold weather and rainy } \\
\text { days }\end{array}$ & $\begin{array}{l}\text { Several layers of plastic bag were used to cover } \\
\text { the jar during cold months }\end{array}$ \\
\hline & $\begin{array}{l}\text { Some producers fermented the steamed rice for } \\
\text { only three days }\end{array}$ & Fermentation is completed in four days or over \\
\hline \multirow{4}{*}{$\begin{array}{l}\text { Distillation of fermented } \\
\text { mash }\end{array}$} & $\begin{array}{l}\text { Short pipe (The material of distillation pot and } \\
\text { the pipe are made of aluminum) }\end{array}$ & $\begin{array}{l}\text { Longer pipe (The material of distillation pot } \\
\text { and the pipe are made of aluminum) }\end{array}$ \\
\hline & $\begin{array}{l}\text { Fermented rice mash (solid and liquid) is } \\
\text { placed directly in the distillation pot }\end{array}$ & $\begin{array}{l}\text { Placed the fermented mash in distillation pot } \\
\text { together but the solid and liquid part is } \\
\text { separated by tray }\end{array}$ \\
\hline & Distillation using firewood as heat source & Distillation using rice husk as heat source \\
\hline & $\begin{array}{l}\text { Rice liquor was not separated into first and } \\
\text { second grade }\end{array}$ & $\begin{array}{l}\text { Rice liquor was classified into first and second } \\
\text { grade; first drippings were separated as this } \\
\text { contain low boiling point alcohol like methanol }\end{array}$ \\
\hline
\end{tabular}

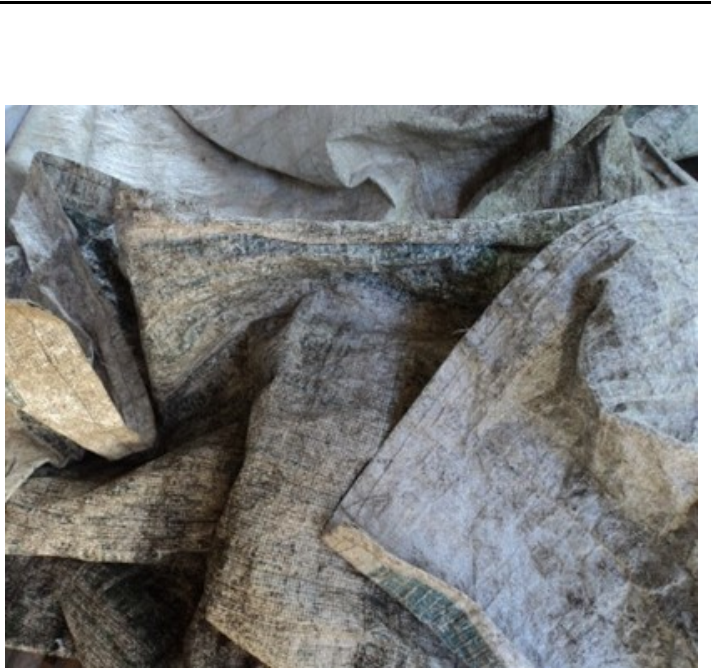

Figure 1. Dirty plastic nets used for mixing cooked rice

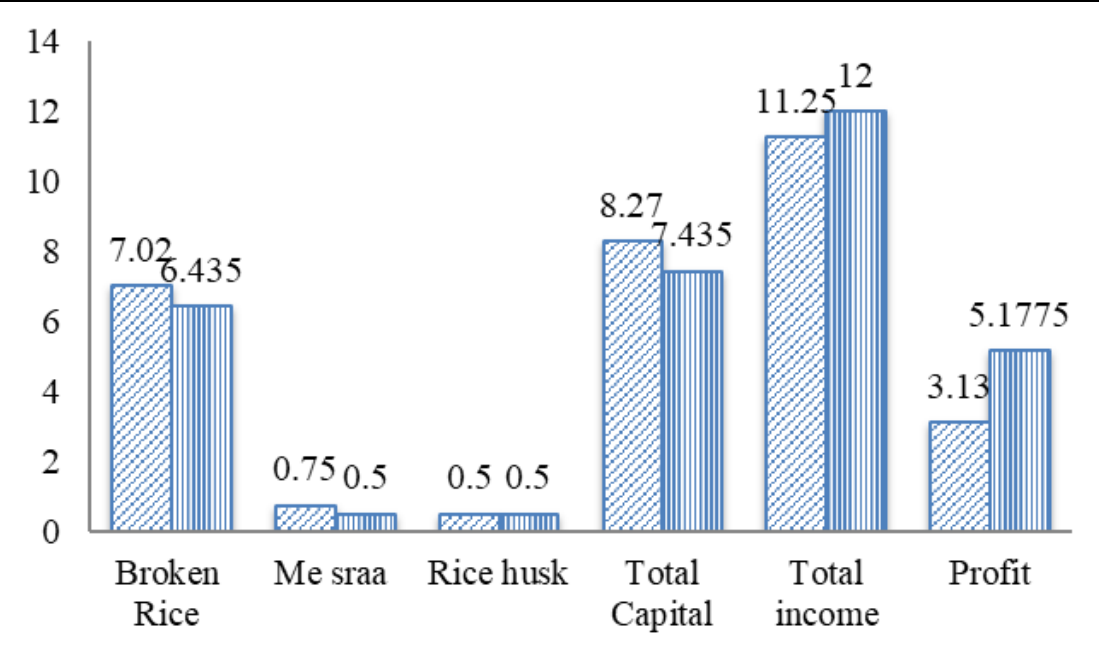

\section{Before 四 After}

Figure 2. Profitability analysis of rice liquor production using traditional and modified method 
and proteins are denatured to make them susceptible to enzyme action by koji. Steaming also sterilizes the grains. During steaming, the grains absorb water to 7$12 \%$ of the starting weight of the rice, thus resulting in a total water gain of about $35-40 \%$ from the beginning of the brewing process. In olden times, and still in small breweries, steam is usually generated from boiling water in a large pot. A boiler is commonly used in many larger breweries for the steaming of rice. In modern sake breweries, two types of continuous steaming apparatus are used, namely a belt conveyor system and a cylinder system. The steamed rice is cooled to nearly $40^{\circ} \mathrm{C}$ for koji making and to about $10^{\circ} \mathrm{C}$ for preparing yeast starter culture and main mash (Kiyoshi and Takeaki, 2004). According to Chim et al. (2011), cooking of rice for srasor processing at Cambodia differs; $48.3 \%$ of the processors used boiling while $46.5 \%$ followed the steaming method. Rice boiling is a traditional method for cooking rice for liquor processing. However, steaming resulted in more acceptable product because the rice is not burn and had better aroma compared to boiled rice.

\subsubsection{Inoculation (mixing rice with starter culture)}

In the traditional method, processor used bare hands to check the temperature during cooling and mixing of cooked rice with the starter culture. This practice of using bare hands subjected the product to crosscontamination. Further, if rice is still very hot, the starter culture will be inactivated causing failed fermentation. In the modified process, a thermometer was used to ensure the temperature of the cooked rice prior to inoculation. Moreover, wearing of gloves by the workers was strictly implemented during mixing to avoid contamination.

\subsubsection{Rice liquor fermentation}

The temperature and condition of the fermenting mash during solid state fermentation (SSF) were observed daily for 48 hours. This is followed by liquid state fermentation (LSF) wherein water was added in each jar at the rate of 1 part milled rice to 3 parts water. During the preparation of saccharified rice, the temperature of the mixture was observed to increase, reaching around $38-40^{\circ} \mathrm{C}$, due to the activities of microorganisms actively breaking the starch into simpler, fermentable sugars. After 48-72 hours, the mixture produced sweet smell, slightly liquefied and having mild alcoholic flavor and aroma indicating that rice starch had been saccharified and sugar was partly converted to alcohol. Biochemical changes occurred during rice saccharification. Firstly, the development of $\alpha$-amylase (liquefying amylase) and amyloglucosidase (saccharifying amylase) that hydrolyzed the rice starch to dextrins, glucose, and maltose. Secondly, the synthesis of acid and alkaline proteases hydrolyzed proteins to peptides and amino acids. Similarly, the temperature of the fermenting mash was checked daily for another 48 hours. The total time of rice liquor fermentation is 96 hours for both SSF and LSF to complete the fermentation process.

Local producers usually ferment the rice for a total of three days for both SSF (2 days) and SLF (1 day). This period is not enough for molds to complete the conversion of starch into fermentable sugars and in the same manner, yeasts cannot maximize the conversion of sugar into ethanol and $\mathrm{CO}_{2}$ resulting in low yield of rice liquor. The fermentable sugar was converted to ethanol by the yeast. Saccharification and fermentation proceeded simultaneously in the unfiltered, dense, mushy mash. This particular set up led to a very high population of yeast cells in the mash and high ethanol content in the rice liquor. In sake production, the starch in steamed rice is being broken down into glucose and the glucose is converted to ethanol. Scientists differentiate the two processes in making wine and sake and are termed as single fermentation for the former and double fermentation in the latter. During fermentation, various biochemical changes occurred in the main mash. First, starch changed to the alpha form by steaming and was saccharified by saccharification amylases to glucose and other sugars such as maltose, isomaltose, and panose. Saccharification by amylases is relatively stable and continues to act in the main mash throughout fermentation. Second, glucose is fermented by yeast to form ethanol and carbon dioxide. Lactic, succinic, and other organic acids are produced during fermentation. In general, the first two acids, being nearly equal in concentration with malic acid, accounted for approximately $90 \%$ of the total organic acids (Iwata et al., 2003). These two processes began in the same way, sharing the common trunk of glycolysis as shown in the alcoholic fermentation pathway.

\subsubsection{Distillation of rice liquor}

As mentioned above, the process of distillation was modified by separating the liquid from the solid portion of the fermented rice mash. The first few dripping was collected and separated as this contains low boiling point alcohol that might contain methanol known to be the toxic compound in most alcohol distillates. The traditional process involved the use of the short pipe, the solid and liquid part of the fermented rice mash are distilled at the same time, used of firewood during distillation, and all the drippings are collected altogether as rice liquor. This method is considered less efficient and very risky since the steamed rice was observed to overflow during boiling and mixed with the rice liquor when the short pipe is used. Also, sticking and burning 
of fermented rice mash at the bottom of the distilling pot happened when the solid and liquid are placed altogether during distillation. The processing of this method of rice liquor is similar to distilled spirit from rice in Southeast Asian countries (Lisdiyanti and Kozaki, 2003) and Lao rice whiskey (Hatsadong and Douangsila, 2006), but it is opposite to sake (Iwata et al., 2003) and whisky (Henderson, 2004).

\subsection{Physicochemical properties and yield (\%) of the rice liquor}

Table 2 shows that the alcohol content of the modified process is higher $(17.52 \%)$ than the traditional method $(16.45 \%)$. All the other physicochemical properties $(\mathrm{pH}, \mathrm{TSS}$, pure alcohol) are significantly higher in modified compared to traditional process except for TTA. Sheorain et al. (2000) reported that the typical yield of alcohol from molasses is $0.225 \mathrm{Lkg}^{-1}$ when molasses contains $45 \%$ sugar, only $70-75 \%$ of the sugars get fermented to alcohol and the remaining sugars go into spent wash. On the other hand, in typical grain fermentation, the alcohol yield is $>0.36 \mathrm{Lkg}^{-1}$ of grain, containing $60 \%$ of starch which corresponds to $85 \%$ of conversion of sugars to alcohol. An addition of sorghum can potentially give a good yield of alcohol of about 0.38 to $0.39 \mathrm{Lkg}^{-1}$ of absolute alcohol per kilogram of grain provided and the process is optimized from 0.32 to 0.33 $\mathrm{Lkg}^{-1}$.

Table 2. Comparative physicochemical properties and yield $(\%)$ of rice liquor using traditional and modified method

\begin{tabular}{lccc}
\hline \multicolumn{1}{c}{ Item } & $\begin{array}{c}\text { Traditional } \\
\text { Process }\end{array}$ & $\begin{array}{c}\text { Modified } \\
\text { Process }\end{array}$ & P \\
\hline Amount of broken rice & 18.00 & 16.50 & \\
(Kg) & & & \\
Amount of starter culture & 30.00 & 20.00 & \\
(g) & 3.00 & 4.00 & \\
Fermentation period (day) & 30.00 & 33.33 & 0.00 \\
Rice liquor produced (L) & 16.45 & 17.52 & 0.03 \\
Alcohol content (\%) & 4.9 & 5.4 & 0.007 \\
pH & 11.2 & 12.5 & 0.067 \\
Total soluble solids & 0.83 & 0.3 & 0.016 \\
$\left({ }^{\circ}\right.$ Brix) & 4.90 & 5.83 & 0.000 \\
Total acidity (\%) & 0.27 & 0.35 & 0.000 \\
Purified alcohol (L) & 166.67 & 202.00 & 0.000 \\
Yield (Lkg & & \\
Yield (\%) & & & \\
\hline
\end{tabular}

Mean values within row with the same letters are not significantly different at $\mathrm{P} \leq 0.05$.

The efficiency of rice liquor production is the most important aspect for the liquor processors and this is measured in terms of yield (Table 2). The result shows that the yield increased from 0.27 to $0.35 \mathrm{LKg}^{1}$ after modification of rice liquor processing. The amount of raw material or milled rice and starter culture used decreased from $18 \mathrm{~kg}$ to $16.5 \mathrm{~kg}$ and from $30 \mathrm{~g}$ to $20 \mathrm{~g}$, respectively and yet the yield was increased. This indicates that the process modification resulted in considerable improvement in yield, implementation of proper sanitation and good hygiene increased the productivity and reduces the risk of rice liquor consumption. The rice liquor produced using the modified method was significantly higher than the traditional process.

\subsection{Profitability of rice liquor processing using modified method}

The economic analysis of rice liquor processing is based on the material and equipment in a cycle processing. However, the economic analysis focuses on the expenditure of material only that was shown in Figure 2. The results showed that the total capital was decreased while the profit was increased twice times if compared to the before and after improvement the technique. For example, the cost of broken rice (6.435\$) was decreased after modification the technique while the previous cost was 7.02\$. However, the material was decreased but the yield of product was increased. On the other hand, the cost of yeasts was reduced from $0.75 \$$ to $0.5 \$$ after modification of technique. To sum up, the profit of rice liquor depended on the amount of production and the production regarded to technical improvement.

\subsection{Sensory test evaluation}

About $61 \%$ of general customers they preferred the rice liquor that improved the basic technique however $36 \%$ they still prefer the traditional rice liquor because they think that in rice liquor has the smell of rice mixed with liquor and they never test the good quality of like that before (Figure 3). Otherwise, the general customers preferred the improve quality because of really smell of liquor, the taste can compare whiskey and after drinking through the month and sore throat, the sweet taste was presented.

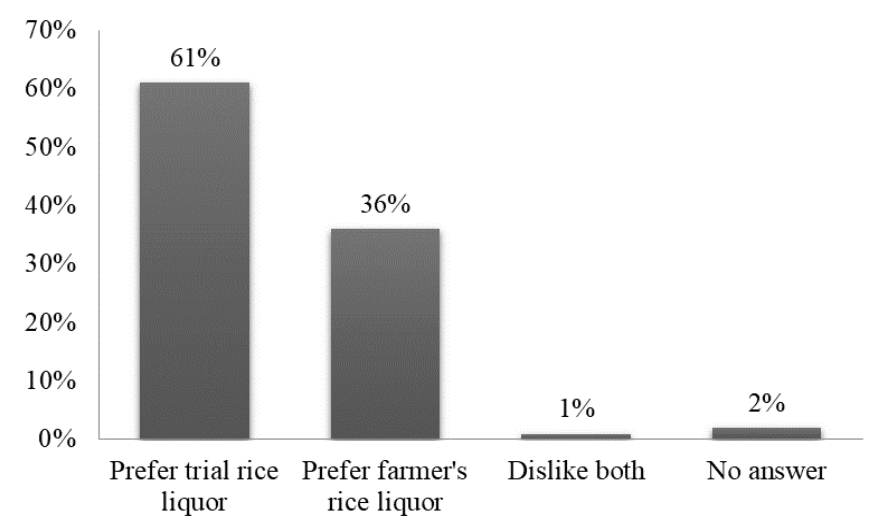

Figure 3. Sensory test evaluation of rice liquor with general customers 


\section{Conclusion}

Rice liquor processing in Cambodia has great potential for further improvement and for upscale production with simple technical modification and adjustments coupled with strict implementation of quality assurance systems. The acceptability of the product; and profitability of production were improved using the modified technique. The use of other local rice varieties, particularly waxy rice, should be tested as raw material for rice wine processing. However, the adoption of the modified method by the local rice liquor producers must be given priority by the proper authorities if we want to have a competitive product. Development of proper packaging design and technology promotion should also be done in the future studies.

\section{Acknowledgment}

The senior author would like to extend his gratitude and appreciation to the Southeast Asian Regional Center for Graduate Study and Research in Agriculture (SEARCA), Philippines, for the scholarship grant; to the Royal University of Agriculture (RUA) and Food Science Cluster, UP Los Baños, Philippines for the opportunity and valuable assistance in the completion of the study; and last but not the least to the srasor processors in Takeo province, Cambodia for providing the needed information.

\section{References}

AOAC (Association of Official Analytical Chemistry). (2000). Official Methods of Analysis. $17^{\text {th }}$ ed. Washington, D.C.: Association of Analytical Chemists, Inc.

Alan, J.B. (2011). Handbook of Alcoholic Beverages: Technical, Analytical and Nutritional Aspects. US: John Wiley and Sons.

Chim, C., Ito, K., Hamano, M., Matsumoto, T. and Mom, S. (2011). Processing of sraasor (rice liquor) in Takeo province, Cambodia. IJERD-International Journal Environmental Development, 2(2), 30-35.

Hatsadong, K., Douangsila, K. and Gibson, P. (2006). Rice-based traditions and rituals in the Mekong river valley. In Schiller, J.M., Chanphengxay, M.B., Linquist, B. and Appa Rao, S. (Eds.) Rice in Laos, p. 65-78. Phillipines: International Rice Research Institute

Henderson, M. (2004). Whiskey.Handbook of Food and Beverage Fermentation Technology. USA: Marcel Dekker, Inc. https:// doi.org/10.1201/9780203913550.ch47

Iwata, H., Suzuki, T. and Aramaki, I. (2003). Purification and characterization of rice a-glucosidase, a key enzyme for alcohol fermentation rice polish. Journal of Bioscience and Bioengineering, 95(1), 106-108. https://doi.org/10.1016/S1389-1723(03)80157-3

Kiyoshi, Y. and Takeaki, I. (2004). Industrialization of Sake Manufacture. In Steinkraus, K. (Ed.) Industrialization of Indigenous Fermented Foods, Revised and Expanded. USA: CRC Press, Technology and Engineering.

Lisdiyanti, P. and Kozaki, M. (2003). Rice wine in South -East Asia countries: Thailand, Lao, Vietnam and Myanmar. The First International Symposium on Insight into the World of Indigenous Fermented Foods for Technology Development and Food Safety, August 13-17, 2003. Kasetsart University, Bangkok, Thailand.

Norman G.M. and Robert B.G. (2006). Principles of Food Sanitation. $5^{\text {th }}$ ed. New York, USA: Springer Science.

Sheorain, V., Banka, R. and Chavan, M. (2000). Ethanol Production from Sorghum. In Chandrasekar, A., Bandyopadhyay, R. and Hall, A.J. (Eds.) Technical and Institutional Options for Sorghum Grain Mold Management, p. 228-239. India: International Crops Research Institute for the Semi-Arid Tropics. 